\title{
D-3-Phosphoglycerate Dehydrogenase
}

National Cancer Institute

\section{Source}

National Cancer Institute. D-3-Phosphoglycerate Dehydrogenase. NCI Thesaurus. Code C99476.

D-3-phosphoglycerate dehydrogenase (533 aa, $257 \mathrm{kDa}$ ) is encoded by the human PHGDH gene. This protein plays a role in the serine biosynthesis pathway. 